\title{
Pyrobaculum calidifontis sp. nov., a novel hyperthermophilic archaeon that grows in atmospheric air
}

\author{
TAKU AMO,${ }^{1}$ MARIA LUZ F. PAJE ${ }^{2}$ AKIKO INAGAKI, ${ }^{1}$ SATOSHI EZAKI, ${ }^{1}$ HARUYUKI \\ ATOMI $^{1}$ and TADAYUKI IMANAKA ${ }^{1,3}$ \\ ${ }^{1}$ Department of Synthetic Chemistry and Biological Chemistry, Graduate School of Engineering, Kyoto University, Yoshida-Honmachi, Sakyo-ku, \\ Kyoto 606-8501, Japan, and Core Research for Evolutional Science and Technology Program of Japan Science and Technology Corporation \\ (CREST-JST), Kawaguchi, Saitama 332-0012, Japan \\ ${ }^{2}$ National Institute of Molecular Biology and Biotechnology, University of the Philippines Los Baños, College Laguna 4031, Philippines \\ ${ }^{3}$ Author to whom correspondence should be addressed (imanaka@sbchem.kyoto-u.ac.jp)
}

Received May 10, 2001; accepted March 1, 2002; published online March 27, 2002

Summary A novel, facultatively aerobic, heterotrophic hyperthermophilic archaeon was isolated from a terrestrial hot spring in the Philippines. Cells of the new isolate, strain VA1, were rod-shaped with a length of 1.5 to $10 \mu \mathrm{m}$ and a width of 0.5 to $1.0 \mu \mathrm{m}$. Isolate VA1 grew optimally at 90 to $95^{\circ} \mathrm{C}$ and pH 7.0 in atmospheric air. Oxygen served as a final electron acceptor under aerobic growth conditions, and vigorous shaking of the medium significantly enhanced growth. Elemental sulfur inhibited cell growth under aerobic growth conditions, whereas thiosulfate stimulated cell growth. Under anaerobic growth conditions, nitrate served as a final electron acceptor, but nitrite or sulfur-containing compounds such as elemental sulfur, thiosulfate, sulfate and sulfite could not act as final electron acceptors. The $\mathrm{G}+\mathrm{C}$ content of the genomic DNA was $51 \mathrm{~mol} \%$. Phylogenetic analysis based on 16S rRNA sequences indicated that strain VA1 exhibited close relationships to species of the genus Pyrobaculum. A DNA-DNA hybridization study revealed a low level of similarity $(\leq 18 \%)$ between strain VA1 and previously described members of the genus Pyrobaculum. Physiological characteristics also indicated that strain VA1 was distinct from these Pyrobaculum species. Our results indicate that isolate VA1 represents a novel species, named Pyrobaculum calidifontis.

Keywords: aerobic respiration, hyperthermophile, nitrate respiration.

\section{Introduction}

Hyperthermophiles are defined as microorganisms that grow optimally at temperatures above $80^{\circ} \mathrm{C}$ (Stetter 1999), or as microorganisms that can grow at temperatures above $90{ }^{\circ} \mathrm{C}$ (Adams and Kelly 1998). A vast number of hyperthermophiles have been isolated from marine hydrothermal systems, heated sediments, terrestrial solfataras and hot springs (Huber and Stetter 1998). They are diverse with respect to their phylogeny and physiological and biochemical properties (Huber and
Stetter 1998). Many hyperthermophiles reported thus far are strictly anaerobic (Amend and Shock 2001), possibly because the availability of oxygen in hydrothermal environments is low as a result of the low solubility of oxygen at high temperatures. All hyperthermophilic members of the Euryarchaeota are strict anaerobes, and respire predominantly by sulfur or sulfate reduction, methanogenesis or fermentation (Huber and Stetter 1998). In Crenarchaeota, a few hyperthermophiles have been found that utilize oxygen as a terminal electron acceptor (Castresana and Moreira 1999). The hyperthermophilic archaeon Aeropyrum pernix has been shown to be an obligate aerobe (Sako et al. 1996), and some Sulfolobus species, with optimal growth temperatures in the range of 80 to $85^{\circ} \mathrm{C}$ (Grogan 1989), can also utilize oxygen (Brock et al. 1972). Furthermore, a neutrophilic facultative aerobe, Pyrobaculum oguniense (Sako et al. 2001), and a few acidophilic facultative aerobes, such as Acidianus infernus (Segerer et al. 1986) and Sulfurisphaera ohwakuensis (Kurosawa et al. 1998), have been identified. There have also been reports on the isolation of facultative microaerobes, including Pyrobaculum aerophilum (Völkl et al. 1993), Pyrolobus fumarii (Blöchl et al. 1997) and Aquifex pyrophilus (Huber et al. 1992), which grow optimally at oxygen concentrations below $5 \%(\mathrm{v} / \mathrm{v})$ in the gas phase (Adams and Kelly 1998).

At present, the genus Pyrobaculum comprises five species: Pyrobaculum islandicum (Huber et al. 1987), P. organotrophum (Huber et al. 1987), P. aerophilum (Völkl et al. 1993), $P$. arsenaticum (Huber et al. 2000) and P. oguniense (Sako et al. 2001). Despite the small number of species, this genus is diverse in terms of the physiological characteristics of its members. Pyrobaculum islandicum and P. organotrophum are strict anaerobes, growing heterotrophically with elemental sulfur or oxidized sulfur-containing compounds as electron acceptors (Huber et al. 1987). Pyrobaculum islandicum can also reduce ferric iron under organotrophic growth conditions (Vargas et al. 1998), and was found to grow chemolithoautotrophically 
with hydrogen, carbon dioxide and elemental sulfur (Huber et al. 1987). Pyrobaculum aerophilum is a marine facultative microaerobe that can grow aerobically at oxygen concentrations up to 5\% (v/v) in the gas phase (Völkl et al. 1993), anaerobically by dissimilatory nitrate or nitrite reduction (Völkl et al. 1993), and chemolithoautotrophically with hydrogen or thiosulfate as electron donors coupled with the reduction of oxygen or nitrate (Völkl et al. 1993). Pyrobaculum arsenaticum is a strict anaerobe, growing chemolithoautotrophically with carbon dioxide as carbon source, hydrogen as electron donor, and arsenate, thiosulfate or elemental sulfur as the electron acceptor (Huber et al. 2000). Pyrobaculum arsenaticum can also grow organotrophically in the presence of an inorganic electron acceptor such as sulfur, selenate or arsenate (Huber et al. 2000). Pyrobaculum oguniense is a facultative aerobe, growing aerobically and microaerobically with oxygen as an electron acceptor (Sako et al. 2001). Under aerobic conditions, growth is inhibited by elemental sulfur, but under anaerobic conditions, elemental sulfur, thiosulfate, L-cystine and oxidized glutathione can be utilized as electron acceptors (Sako et al. 2001).

Here, we report the isolation and characterization of a novel facultatively aerobic, hyperthermophilic archaeon that displays vigorous growth in atmospheric air.

\section{Materials and methods}

\section{Strains}

Pyrobaculum aerophilum JCM $9630^{\mathrm{T}}$, P. organotrophum JCM $9190^{\mathrm{T}}$ and Thermoproteus tenax JCM $9277^{\mathrm{T}}$ were purchased from the Japan Collection of Microorganisms (JCM; Wako, Japan). Pyrobaculum islandicum DSM $4184^{\mathrm{T}}$ was a gift from Prof. Toshihisa Ohshima (Tokushima University, Tokushima, Japan). Pyrobaculum oguniense $\mathrm{TE}^{\mathrm{T}}\left(=\mathrm{JCM} 10595^{\mathrm{T}}\right)$ was kindly provided by Prof. Yoshihiko Sako (Kyoto University, Kyoto, Japan).

\section{Collection of samples}

Water and mud samples were collected from various hot springs in Los Baños and Calamba, Laguna, the Philippines. A hyperthermophilic archaeon, Caldivirga maquilingensis, was previously isolated from this field (Itoh et al. 1999). The in situ temperatures ranged from 45 to $85{ }^{\circ} \mathrm{C}$. Mud samples were acidic (pH 1.8 to 3.2 ) and water samples were near neutral ( $\mathrm{pH}$ 7.4). The major cations present in the water samples, from which strain VA1 was isolated, were (in $\mathrm{mg}^{-1}$ ): calcium, 45.2; magnesium, 16.5; potassium, 73.5; and sodium, 599. The samples were transported to the laboratory in sterile plastic tubes (Nunc A/S, Roskilde, Denmark) without temperature control and kept at $4{ }^{\circ} \mathrm{C}$ until isolation procedures were performed.

\section{Enrichment culture conditions for the isolation of strain VAI}

The enrichment medium contained (per liter of deionized water): $1.0 \mathrm{~g}$ yeast extract (Nakalai Tesque, Kyoto, Japan); $1.0 \mathrm{~g}$ tryptone (Nakalai Tesque); $110 \mathrm{mg} \mathrm{MgSO}_{4} \cdot 7 \mathrm{H}_{2} \mathrm{O} ; 52 \mathrm{mg}$ $\mathrm{CaCl}_{2} \cdot 2 \mathrm{H}_{2} \mathrm{O} ; 40 \mathrm{mg} \mathrm{FeCl}_{3} ; 25 \mathrm{mg} \mathrm{FeSO}_{4} \cdot 7 \mathrm{H}_{2} \mathrm{O} ; 19 \mathrm{mg}$
$\mathrm{Na}_{2} \mathrm{SO}_{4} ; 10 \mathrm{mg} \mathrm{KCl} ; 2.5 \mathrm{mg} \mathrm{MnSO}_{4} \cdot 5 \mathrm{H}_{2} \mathrm{O} ; 0.8 \mathrm{mg}$ $\mathrm{ZnSO}_{4} \cdot 7 \mathrm{H}_{2} \mathrm{O} ; 0.4 \mathrm{mg} \mathrm{CuSO}{ }_{4} \cdot 5 \mathrm{H}_{2} \mathrm{O} ; 0.3 \mathrm{mg} \mathrm{Na} \mathrm{SO}_{3}$; and $0.2 \mathrm{mg} \mathrm{CoCl} \cdot 6 \mathrm{H}_{2} \mathrm{O}$. The $\mathrm{pH}$ of the enrichment medium was adjusted to 7.0 with $\mathrm{NaOH}$ at room temperature before autoclaving. The enrichment was performed in test tubes $(180 \mathrm{~mm} \times 18 \mathrm{~mm}$; Iwaki, Tokyo, Japan) with silicone plugs (Top, Kyoto, Japan) containing $10 \mathrm{ml}$ of medium and incubated at $85{ }^{\circ} \mathrm{C}$ in atmospheric air without shaking. For isolation, the enrichment medium was solidified with $0.8 \%$ Gelrite in slanted media bottles (Iwaki). The medium was supplemented with $5 \mathrm{mM} \mathrm{MgSO}_{4}$ and $1.25 \mathrm{mM} \mathrm{CaCl}_{2}$ for solidification of the medium. After applying the samples, the slants were incubated at $85^{\circ} \mathrm{C}$.

\section{Growth experiments with strain VAI}

Unless otherwise stated, routine liquid cultivations were performed in medium containing $10 \mathrm{~g}$ of tryptone and $1.0 \mathrm{~g}$ of yeast extract per liter of deionized water (TY medium) at $90{ }^{\circ} \mathrm{C}$ in an appropriate gas phase. Aerobic cultures in atmospheric air were performed in 100 or $1000 \mathrm{ml}$ media bottles (Iwaki) with silicone plugs (Top) containing 50 or $200 \mathrm{ml}$ of medium, respectively, without shaking, or in 500-ml shaking flasks (Iwaki) with silicone plugs (Top) containing $200 \mathrm{ml}$ of medium with vigorous shaking (120 rpm). Anaerobic culture conditions were maintained as described by Balch et al. (1979). Vial bottles (20 ml volume, Maruemu, Osaka, Japan) containing $10 \mathrm{ml}$ medium were autoclaved and transferred to an anaerobic chamber (Tabai Espec, Osaka, Japan) filled with an anoxic gas mixture $\left(\mathrm{N}_{2}: \mathrm{CO}_{2}: \mathrm{H}_{2}, 90: 5: 5\right)$. In the chamber, trace oxygen was reduced by adding $0.5 \mathrm{mM} \mathrm{Na}_{2} \mathrm{~S}$ and then the bottle was sealed with a butyl rubber stopper (Maruemu) and an aluminum cap (Maruemu). Resazurin $\left(1 \mathrm{mg} \mathrm{l}^{-1}\right)$ was used as a redox indicator. Microaerobic growth conditions were obtained by omitting the addition of $\mathrm{Na}_{2} \mathrm{~S}$. The presence of oxygen was confirmed by the color of resazurin.

\section{Light and electron microscopy}

Cells were observed with an Eclipse E800 light microscope (Nikon, Tokyo, Japan) with immersion oil. For scanning electron microscopic observation, samples were prepared as follows. Diluted cultures were applied to thin glass coated with poly-L-lysine (Sigma, St. Louis, MO). Cells were fixed with 2.5\% glutaraldehyde solution in potassium phosphate buffer $(\mathrm{pH}$ 7.2) and washed five times with the potassium phosphate buffer. Samples were dehydrated with a series of acetone solutions and washed with tertiary butanol. After freezing at $4{ }^{\circ} \mathrm{C}$, samples were freeze-dried (ES-2030, Hitachi, Tokyo, Japan). The dried samples were carefully mounted on aluminum stubs with double-sided adhesive tape. A conductive pathway was established between the specimen and the stub with conductive paint (ThreeBond, Tokyo, Japan). The mounted specimens were sputter coated with palladium in an E-1030 ion sputter (Hitachi) before observation with an S-4700 scanning electron microscope (Hitachi).

\section{Substrate utilization}

To determine substrate utilization by VA1, cells were culti- 
vated in a modified basal salt (BS) medium (Völkl et al. 1993), containing (per liter of deionized water): $1.4 \mathrm{~g} \mathrm{KH}_{2} \mathrm{PO}_{4} ; 0.25 \mathrm{~g}$ $\mathrm{NH}_{4} \mathrm{Cl} ; 0.22 \mathrm{~g} \mathrm{NaHCO}_{3} ; 0.2 \mathrm{mg}\left(\mathrm{NH}_{4}\right)_{2} \mathrm{Fe}\left(\mathrm{SO}_{4}\right)_{2} \cdot 6 \mathrm{H}_{2} \mathrm{O}$; $0.1 \mathrm{mg} \mathrm{Na} 2 \mathrm{SeO}_{4} ; 0.1 \mathrm{mg} \mathrm{Na} \mathrm{WO}_{4} \cdot 2 \mathrm{H}_{2} \mathrm{O}$; and $10 \mathrm{ml}$ trace mineral solution (Balch et al. 1979). The substrates-yeast extract, tryptone, peptone (Difco, Detroit, MI), Casamino acids (Difco), nitrogen base without amino acids (Difco), nutrient broth (Nissui, Tokyo, Japan), glucose, maltose, lactose, starch, pyruvate, succinate and acetate-were added to a concentration of $0.1 \%(\mathrm{w} / \mathrm{v})$.

When we investigated the electron acceptors, VA1 was cultivated anaerobically in a medium containing only $0.3 \%$ tryptone. The following potential electron acceptors were added to the medium at $0.3 \%(\mathrm{w} / \mathrm{v})$ : elemental sulfur, sodium thiosulfate pentahydrate, sodium sulfate, sodium sulfite, sodium nitrate and sodium nitrite. Ferric chloride hexahydrate was added to a concentration of $5 \mathrm{mg} \mathrm{l}^{-1}$.

\section{Gas analysis}

Oxygen, nitrogen and nitrous oxide were analyzed qualitatively with a GC-17A gas chromatograph (Shimadzu, Kyoto, Japan) with a SHINCARBON T column (60/80 mesh; Shinwa Chemical, Kyoto, Japan) and argon as the carrier gas.

\section{Growth measurements}

Strain VA1 was cultivated in TY medium at $90{ }^{\circ} \mathrm{C}$ in atmospheric air. Growth was determined by measuring optical density at $660 \mathrm{~nm}\left(\mathrm{OD}_{660}\right)$. It was confirmed that the $\mathrm{OD}_{660}$ was proportional to the number of cells directly counted with a bacteria-counting chamber (depth, $0.02 \mathrm{~mm}$; Erma, Tokyo, Japan).

The optimal growth temperature and $\mathrm{pH}$ of strain VA1 were determined with cells grown in TY medium. Culture media were adjusted to various $\mathrm{pH}$ values with the following buffer systems at concentrations of $20 \mathrm{mM}$; sodium succinate $(\mathrm{pH} 4.5$ to 6.0), MES (2-( $N$-morpholino)ethanesulfonic acid) (pH 5.5 to 7.0), PIPES (piperazine- $N, N^{\prime}$-bis-(2-ethanesulfonic acid)) (pH 6.5 to 7.5), HEPES ( $N$-2-hydroxyethylpiperazine$N^{\prime}$-2-ethanesulfonic acid) (pH 7.0 to 8.0), Tricine ( $N$-(tris(hydroxymethyl)methyl)glycine) (pH 7.5 to 8.5 ), and Bicine ( $N, N$-(bis-2-hydroxyethyl)glycine) ( $\mathrm{pH} 8.0$ to 8.5 ). The $\mathrm{pH}$ of the medium was adjusted with $\mathrm{HCl}$ or $\mathrm{NaOH}$ at room temperature. Optimal temperature was examined in TY medium at $\mathrm{pH}$ 7.0. Optimal salt concentration was investigated with various concentrations of $\mathrm{NaCl}$ in $\mathrm{TY}$ medium. Doubling times were calculated from the slopes of the growth curves.

\section{Antibiotic sensitivity}

To determine antiobiotic sensitivity, VA1 was cultivated aerobically in TY medium supplemented with $0.3 \%$ thiosulfate. Chloramphenicol (Sigma), penicillin G (Sigma), rifampicin (Nakalai Tesque), streptomycin (Sigma) and vancomycin (Sigma) were tested at final concentrations of $100 \mu \mathrm{g} \mathrm{ml}^{-1}$. Cells were grown at $80{ }^{\circ} \mathrm{C}$, as for other Pyrobaculum species (Huber et al. 1987, Sako et al. 2001).

\section{DNA manipulations}

Routine DNA manipulations were performed by standard methods (Sambrook and Russell 2001). A lambda phage library of VA1 was prepared by ligating genomic DNA partially digested with Sau3AI into BamHI-digested arms of lambda EMBL3 (Stratagene, La Jolla, CA). For isolation of plasmid and phage DNA, Plasmid Mini-, Midi- and Lambda Kits (Qiagen, Hilden, Germany) were used. Restriction enzymes and other modifying enzymes were purchased from Takara Shuzo (Kyoto, Japan) or Toyobo (Osaka, Japan).

\section{DNA base composition}

The $\mathrm{G}+\mathrm{C}$ content of the genomic DNA was determined by high-performance liquid chromatography (HPLC) as previously described (Tamaoka and Komagata 1984) with a DNAGC kit (Yamasa, Chiba, Japan).

\section{$16 S$ rRNA gene sequence analysis}

Two primers, RS1 (5'-AACT(C/T)AAA(G/T)GAATTGAC GG-3') and RS3 (5'-ACGGGCGGTGTGT(A/G)C-3'), were used to amplify a $16 \mathrm{~S}$ rRNA gene fragment using genomic DNA as template. A phage clone, which carried the complete 16S rRNA gene, was screened from the genomic library by plaque hybridization using the amplified gene fragment as a probe. Sequencing of both DNA strands was performed with the ABI PRISM kit and Model 310 capillary DNA sequencer (Perkin-Elmer Applied Biosystems, Foster City, CA). The sequence data were analyzed with the GENETYX-WIN software package, Version 4 (Software development, Tokyo, Japan). Multiple DNA sequence alignment was performed with the ALIGN program contained within the ClustalW program (Thompson et al. 1994) provided by the DNA Data Bank of Japan (DDBJ). The phylogenetic tree was constructed by the neighbor-joining method (Saitou and Nei 1987) after alignment of $1350 \mathrm{bp}$. Bootstrap resampling was performed with the BSTRAP program 1000 times. The tree topology was confirmed by the maximum-likelihood method (Felsenstein 1981) with the fastDNAmL program (Olsen et al. 1994).

\section{DNA-DNA hybridization}

DNA-DNA hybridization was carried out at Higeta Shoyu (Chiba, Japan) using photobiotin- (Vector Laboratories, Burlingame, CA) labeled probes in microplate wells as described elsewhere (Ezaki et al. 1989, Takagi et al. 1993). The templates and biotinylated probes were used at levels of $1.0 \mu \mathrm{g}$ and $20 \mathrm{ng}$ per well, respectively. Hybridization was performed at $37^{\circ} \mathrm{C}$ for $12 \mathrm{~h}$. The DNA reassociation ratios were determined with streptavidin-peroxidase (Zymed Laboratories, San Francisco, CA) and 3,3',5,5'-tetramethylbenzidine (Dojindo, Kumamoto, Japan) (Hara et al. 1991) and estimated with a microplate reader at $620 \mathrm{~nm}$.

\section{Nucleotide sequence accession number}

The 16S rRNA gene sequence of VA1 is available under the Accession No. AB078332 in the GenBank, EMBL and DDBJ databases. 


\section{Results}

\section{Enrichment and isolation}

As a source for isolation of novel hyperthermophiles, we collected 10 water and two mud samples from various terrestrial hot springs in Los Baños and Calamba, Laguna, the Philippines. To enrich the samples for hyperthermophiles that grow under aerobic conditions, silicone-plugged test tubes containing $10 \mathrm{ml}$ of enrichment medium were inoculated with $1 \mathrm{ml}$ of sample and incubated at $85{ }^{\circ} \mathrm{C}$ without shaking. After 3 days, rod-shaped cells were observed in one enrichment culture that had been inoculated with water sample VA, and growth was reproducible through consecutive reinoculation to the same medium.

Isolation of microorganisms in the enrichment culture was performed by serial dilution followed by spreading on slant medium solidified with $0.8 \%$ Gelrite. Slants were incubated at $85^{\circ} \mathrm{C}$, and after 4 days, 200 - $\mu$ l samples of a 1000-fold dilution of the enrichment culture $\left(\mathrm{OD}_{660}=0.08\right)$ produced $30-60$ colonies. Colonies were round, with a diameter of approximately $1 \mathrm{~mm}$. Single colonies were transferred to liquid medium and cultivated. Single colony isolation and liquid cultivation were repeated three times. Because growth characteristics and morphology were consistent, we designated the isolate as strain VA1, and pursued further characterization of the strain.

\section{Morphology}

We observed strain VA1 with a phase contrast microscope and a scanning electron microscope. Cells were rod-shaped, with a length of 1.5 to $10 \mu \mathrm{m}$ and a width of 0.5 to $1.0 \mu \mathrm{m}$, as determined by phase contrast microscopy. The widths of the cells were slightly shorter in the scanning electron micrographs (Figure 1), likely because of contraction during sample preparation. Motility was observed with a phase contrast microscope and was enhanced by heating. Aggregation was also observed, especially in stationary phase cultures.

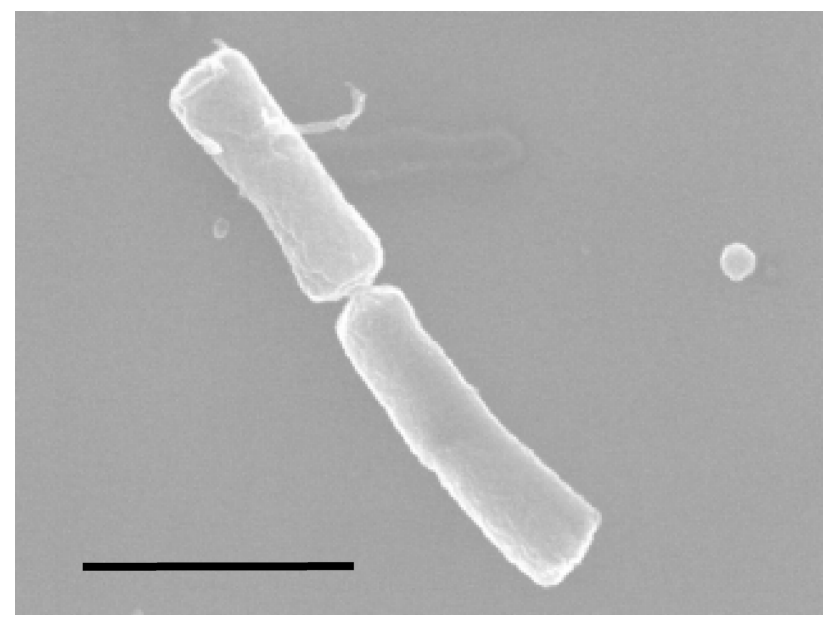

Figure 1. Scanning electron micrograph of isolate VA1 in pairs. Bar = $1 \mu \mathrm{m}$.

\section{Energy and carbon sources}

To determine substrates that could be utilized by strain VA1, we added various substrates to BS medium. Cultures were incubated at $90{ }^{\circ} \mathrm{C}$ in atmospheric air without shaking. Isolate VA1 grew consistently on proteinaceous complex substrates $(0.1 \% \mathrm{w} / \mathrm{v})$ such as yeast extract $\left(\mathrm{OD}_{660}=0.027\right)$, tryptone $\left(\mathrm{OD}_{660}=0.029\right)$, nutrient broth $\left(\mathrm{OD}_{660}=0.041\right)$, peptone $\left(\mathrm{OD}_{660}=0.063\right)$ and Casamino acids $\left(\mathrm{OD}_{660}=0.027\right)$. Slight growth inhibition was observed at higher concentrations of yeast extract. We also found that these substrates could support growth alone, i.e., without basal salts. Yeast nitrogen base without amino acids, glucose, maltose, lactose, starch, pyruvate, succinate and acetate did not support growth, whereas TY medium was the most effective for supporting growth $\left(\mathrm{OD}_{660}>0.07\right)$.

\section{Gas phase and electron acceptors}

Because strain VA1 grew in atmospheric air, we pursued the possibility that it was an aerobic hyperthermophile. To exclude contaminant electron acceptors, a medium containing only $0.3 \%$ tryptone was used in these experiments. Strain VA1 grew in this medium when the gas phase was atmospheric air. In sealed cuvettes, oxygen consumption was detected by gas chromatography (data not shown). In contrast, when the gas phase was replaced with anoxic gas $\left(\mathrm{N}_{2}: \mathrm{CO}_{2}: \mathrm{H}_{2}, 90: 5: 5\right)$, no growth was observed. Various electron acceptors were added to the medium and growth was examined in the anoxic gas atmosphere. Elemental sulfur, which can be utilized by Acidianus infernus (Segerer et al. 1986) and P. oguniense (Sako et al. 2001), did not support growth of VA1. Thiosulfate, which can be utilized by P. oguniense (Sako et al. 2001) and Pyrolobus fumarii (Blöchl et al. 1997), also did not serve as an electron acceptor. Other sulfur compounds, such as sulfate and sulfite, did not support growth. When nitrate was added, VA1 cells exhibited consistent growth, indicating that nitrate could replace oxygen as a terminal electron acceptor, as in $P$. aerophilum (Völkl et al. 1993). However, nitrite could not be utilized by strain VA1 as a single electron acceptor, also like P. aerophilum (Völkl et al. 1993). We examined the products of nitrate reduction, and found that nitrogen production could be detected by gas chromatography, whereas nitrous oxide could not. Addition of ferric iron, an electron acceptor in P. islandicum (Vargas et al. 1998), did not support growth of VA1. The results indicate that strain VA1 is a facultative aerobe that can utilize oxygen and nitrate as electron acceptors under aerobic and anaerobic conditions, respectively. We also examined the growth of strain VA1 under microaerobic conditions. Medium without nitrate was prepared in the anaerobic chamber (see Materials and methods), but addition of the reducing reagent $\mathrm{Na}_{2} \mathrm{~S}$ was omitted. In this case, medium with the redox indicator resazurin was red in color. Growth was observed for approximately $24 \mathrm{~h}$, until the medium became transparent. The results indicated that strain VA1 utilized oxygen under microaerobic conditions, but ceased growth when oxygen was depleted.

The growth curves of strain VA1 under aerobic conditions in 
TY medium at $90{ }^{\circ} \mathrm{C}$ are shown in Figure 2. Vigorous shaking of the culture slightly enhanced growth rates. Sako et al. (1996, 2001) reported that thiosulfate enhanced the aerobic growth of Aeropyrum pernix and P. oguniense, and we observed the same growth enhancement of strain VA1. Although thiosulfate did not serve as an electron acceptor, the addition of $0.3 \%$ thiosulfate significantly stimulated cell growth (Figure 2). An $\mathrm{OD}_{660}$ of 0.53 ( 1.4 g wet cells per liter of culture) could be obtained with vigorous shaking in TY medium with $0.3 \%$ thiosulfate. Elemental sulfur has been reported to inhibit cell growth of $P$. aerophilum (Völkl et al. 1993) and P. oguniense (Sako et al. 2001), and this was also the case for strain VA1 in atmospheric air with vigorous shaking (data not shown).

\section{Antibiotic sensitivity}

We investigated the sensitivity of strain VA1 to various antibiotics. Strain VA1 was resistant to chloramphenicol, penicillin $\mathrm{G}$, streptomycin and vancomycin at concentrations of $100 \mu \mathrm{g}$ $\mathrm{ml}^{-1}$. However, VA1 was sensitive to rifampicin $\left(100 \mu \mathrm{g} \mathrm{ml}^{-1}\right)$. Pyrobaculum islandicum, P. oguniense and P. organotrophum display the same sensitivities to antibiotics (Huber et al. 1987), although $P$. oguniense is also slightly inhibited by chloramphenicol and penicillin G (Sako et al. 2001).

\section{Optimal growth conditions}

We examined growth of strain VA1 under aerobic conditions in medium containing $1.0 \%$ tryptone, $0.1 \%$ yeast extract and $0.3 \%$ thiosulfate. Strain VA1 grew well between 80 and $98{ }^{\circ} \mathrm{C}$, and at a lower rate from 75 to $100{ }^{\circ} \mathrm{C}$. The optimum growth temperature was 90 to $95^{\circ} \mathrm{C}$, with a doubling time of $5.5 \mathrm{~h}$ (Figure 3A). Growth of isolate VA1 was observed in a $\mathrm{pH}$

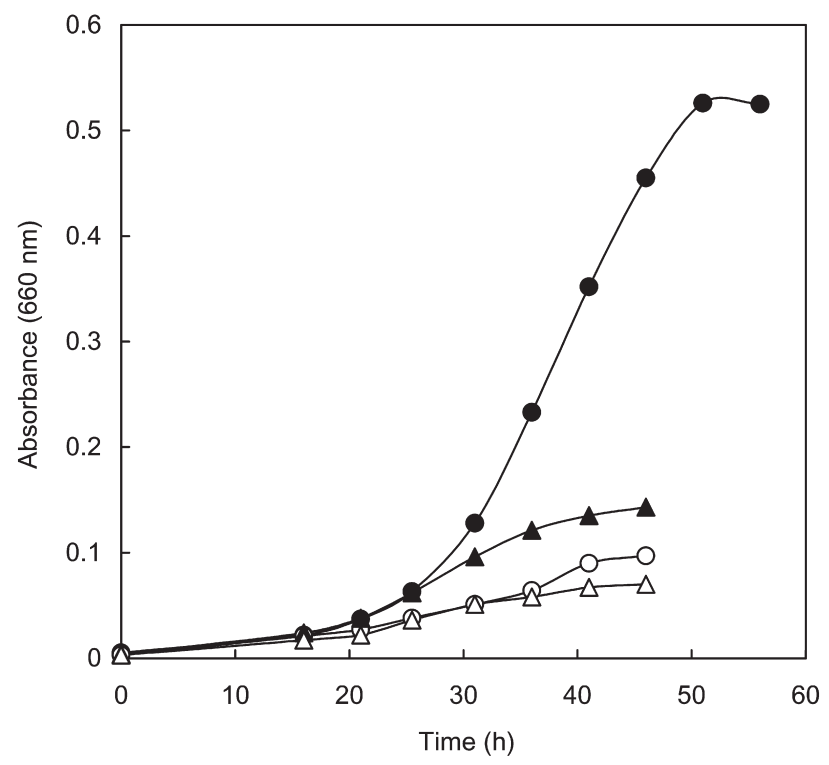

Figure 2. Growth curves of strain VA1 in atmospheric air. Strain VA1 was cultivated at $90^{\circ} \mathrm{C}$ in TY medium without shaking $(\triangle)$ and with shaking $(\bigcirc)$, and in TY medium supplemented with $0.3 \%$ thiosulfate without shaking $(\mathbf{\Delta})$ and with shaking $(\bullet)$.
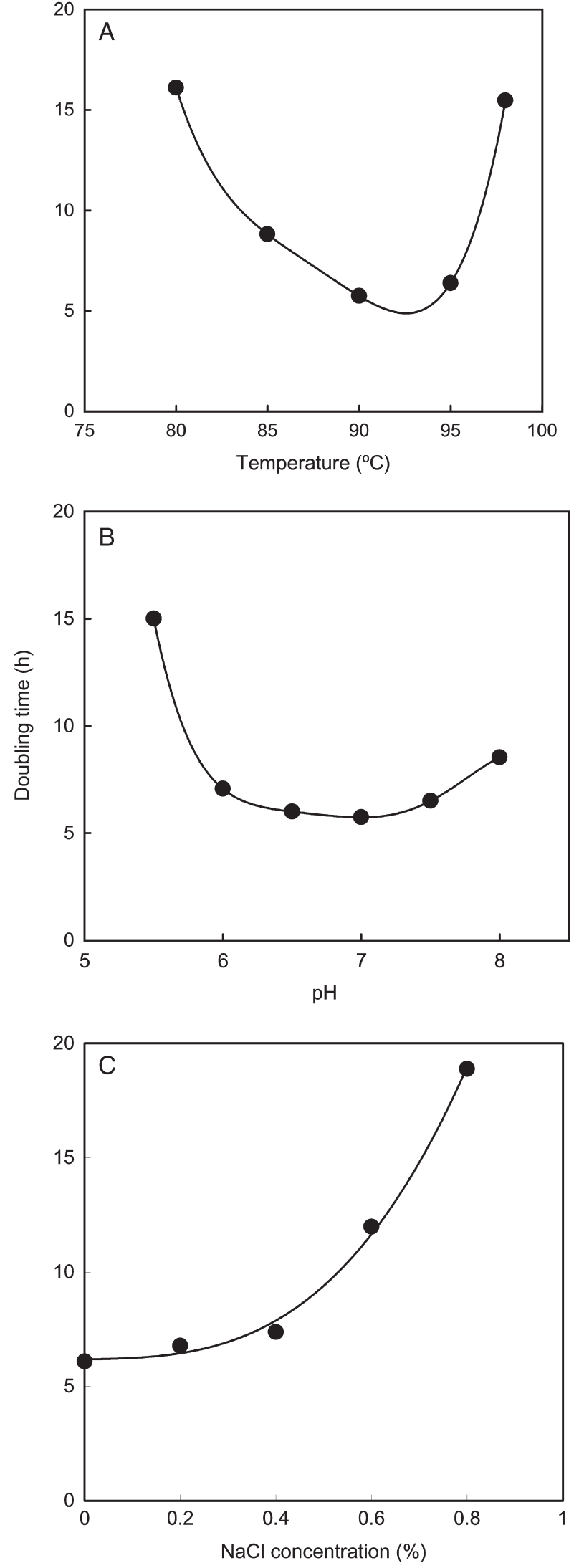

Figure 3. Effect of temperature (A), $\mathrm{pH}$ (B) and $\mathrm{NaCl}$ concentration (C) on aerobic growth of isolate VA1 in TY medium. Doubling times were calculated from the slopes of the growth curves (not shown). 
range of 5.5 to 8.0, with an optimum around $\mathrm{pH} 7.0$ (Figure $3 \mathrm{~B}$ ). Isolate VA1 grew in the culture medium at salt concentrations of up to $0.8 \% \mathrm{NaCl}$, but optimal growth was obtained with no $\mathrm{NaCl}$ (Figure 3C).

\section{DNA base composition}

The $\mathrm{G}+\mathrm{C}$ content of the genomic DNA of isolate VA1, as determined by HPLC, was $51 \mathrm{~mol} \%$.

\section{Phylogenetic analysis}

A total of 1498 nucleotides of the 16S rRNA gene from isolate VA1 were sequenced. A 1350 base pair region (positions 33 to 1382) was aligned with $16 \mathrm{~S}$ rRNA sequences from various archaeal and bacterial species. Isolate VA1 was closely related to the Pyrobaculum spp., namely $P$. oguniense (similarity of 16S rRNA sequence: $97.9 \%)$, P. aerophilum (97.7\%), P. arsenaticum $(97.6 \%)$ and $P$. islandicum $(97.5 \%)$, compared with Thermoproteus tenax $(96.4 \%)$, the type species of the genus Thermoproteus. Phylogenetic trees were constructed by the neighbor-joining method (Figure 4) and maximum-likelihood method (not shown). On both phylogenetic trees, isolate VA1 clustered with members of the genus Pyrobaculum.

\section{DNA-DNA hybridization}

We performed DNA-DNA hybridization experiments with strain VA1, P. aerophilum, P. islandicum, P. oguniense, P. org-

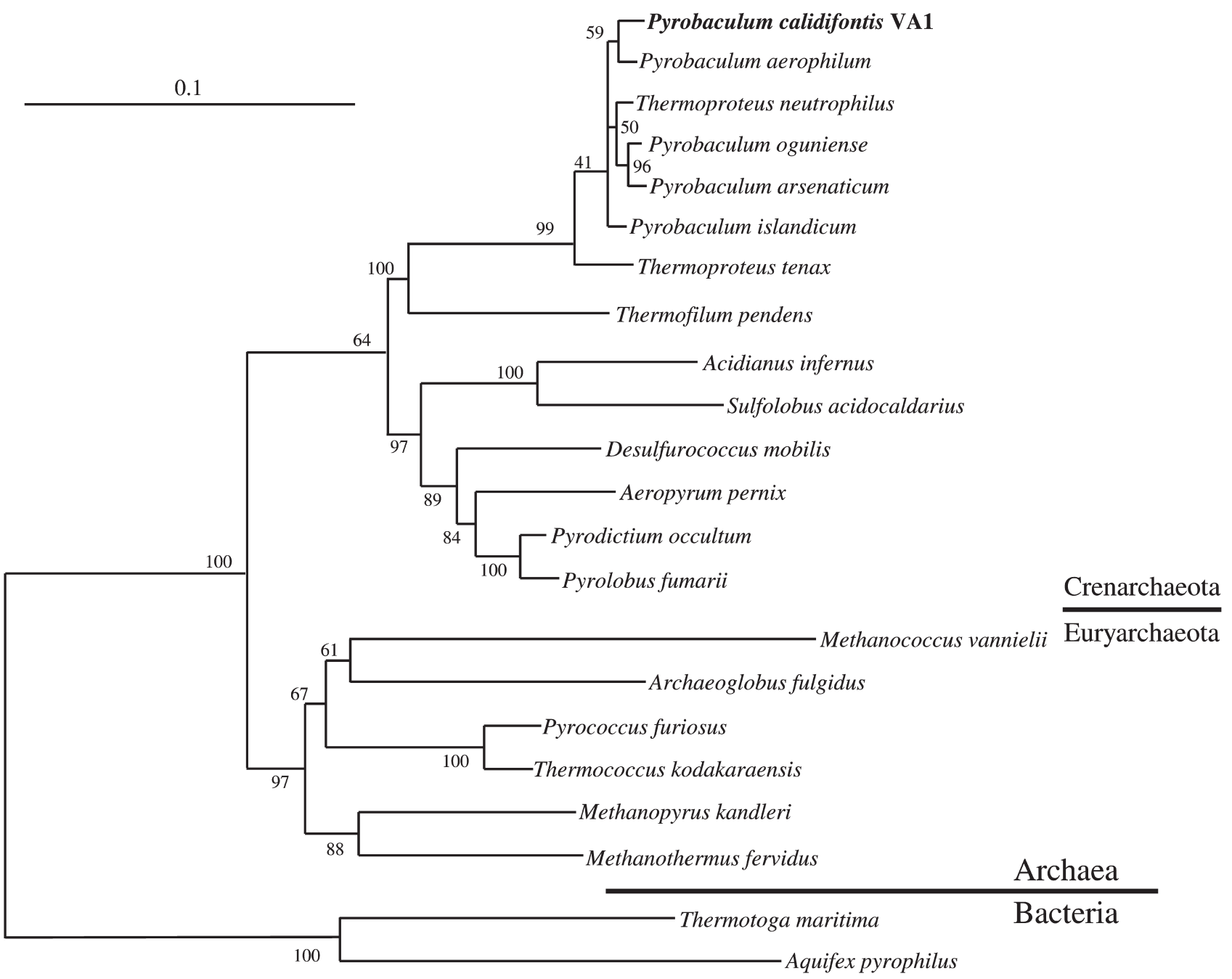

Figure 4. Phylogenetic tree based on 16S rRNA gene sequences showing the position of Pyrobaculum calidifontis (strain VA1). Multiple sequence alignments were performed with ClustalW. Tree topology and evolutionary distance estimations were performed by the neighbor-joining method. Scale bar indicates 10 substitutions per 100 nucleotides. Numbers represent bootstrap probabilities (\%). The accession numbers are as follows: Acidianus infernus, D85505; Aeropyrum pernix, AB008745; Aquifex pyrophilus, M83548; Archaeoglobus fulgidus, Y00275; Desulfurococcus mobilis, M36474; Methanococcus vannielii, M36507; Methanopyrus kandleri, M59932; Methanothermus fervidus, M59145; Pyrobaculum aerophilum, L07510; Pyrobaculum arsenaticum, AJ277124; Pyrobaculum calidifontis, AB078332; Pyrobaculum islandicum, L07511; Pyrobaculum oguniense, AB029339; Pyrococcus furiosus, U20163; Pyrodictium occultum, M21087; Pyrolobus fumarii, X99555; Sulfolobus acidocaldarius, D14876; Thermococcus kodakaraensis, D38650; Thermofilum pendens, X14835; Thermoproteus neutrophilus, AB009618; Thermoproteus tenax, M35966; and Thermotoga maritima, M21774. 
anotrophum and T. tenax. Strain VA1 exhibited low hybridization values with other species of the genus Pyrobaculum and with T. tenax. The highest value (18\%) was obtained with P. aerophilum (Table 1).

\section{Discussion}

Phylogenetic analysis based on $16 \mathrm{~S}$ rRNA gene sequences indicated that strain VA1 was closely related to members of the genus Pyrobaculum. Thermoproteus tenax, the type species of the genus Thermoproteus (Zillig et al. 1981), was less closely related and was not included in the cluster of Pyrobaculum spp. Observations of optimal growth temperature and $\mathrm{pH}$ provide further support for the conclusion that strain VA1 is a member of the genus Pyrobaculum, rather than Thermoproteus (Table 2 ).

Based on 16S rRNA gene sequences, Thermoproteus neutrophilus was included in the cluster of Pyrobaculum spp. However, strain VA1 is different from T. neutrophilus (Table 2), because T. neutrophilus is a strictly anaerobic sulfur-reducer (Fischer et al. 1983), whereas strain VA1 can grow under anaerobic conditions by reducing nitrate, but not sulfur, and is a facultative aerobe. We also observed a significant difference between the $\mathrm{G}+\mathrm{C}$ content of T. neutrophilus ( $60 \mathrm{~mol} \%$ ) (Itoh et al. 1998) and that of strain VA1 (51 mol\%).

At present, the genus Pyrobaculum comprises five species: Pyrobaculum islandicum (Huber et al. 1987), P. organotrophum (Huber et al. 1987), P. aerophilum (Völkl et al. 1993), $P$. arsenaticum (Huber et al. 2000) and P. oguniense (Sako et al. 2001). Pyrobaculum islandicum, P. organotrophum and $P$. arsenaticum are strictly anaerobic (Table 2), distinguishing these species from strain VA1, which is facultatively aerobic. Moreover, strain VA1 can utilize nitrate as an electron acceptor under anaerobic growth conditions, whereas $P$. islandicum, $P$. organotrophum and $P$. arsenaticum mainly utilize sulfur compounds (Table 2).

Like strain VA1, Pyrobaculum aerophilum can use oxygen and nitrate as electron acceptors (Völkl et al. 1993); however, $P$. aerophilum is a facultative microaerobe that can grow at oxygen concentrations only up to $5 \%(\mathrm{v} / \mathrm{v})$ in the gas phase (Völkl et al. 1993). Strain VA1 displayed active growth in atmospheric air. When we performed aerobic cultivation with vigorous shaking, growth was further enhanced. Therefore, strain VA1 can be considered facultatively aerobic, and not microaerobic. In addition, $P$. aerophilum was isolated from a boiling marine water hole and grew optimally at $1.5 \% \mathrm{NaCl}$ (Völkl et al. 1993). On the other hand, strain VA1 was isolated from a terrestrial hot spring and is capable of growth only at $\mathrm{NaCl}$ concentrations of $0.8 \%$ or less.

Like strain VA1, Pyrobaculum oguniense is facultatively aerobic (Sako et al. 2001). Under anaerobic growth conditions, $P$. oguniense depends on sulfur-containing compounds such as elemental sulfur, thiosulfate, L-cystine and oxidized glutathione (Sako et al. 2001). Under aerobic conditions, $P$. oguniense cannot use nitrate as an electron acceptor. Conversely, strain VA1 can utilize nitrate, but not sulfur-containing compounds, anaerobically.

Although strain VA1 is a member of the genus Pyrobaculum, it is distinct from other members of the genus. DNA-DNA hybridization studies strongly support this conclusion (Table 1). Our results indicate that strain VA1 is a new species within the genus Pyrobaculum, which we name Pyrobaculum calidifontis. The type strain is isolate VA1.

As for Aeropyrum pernix (Sako et al. 1996) and P. oguniense (Sako et al. 2001), thiosulfate dramatically stimulated growth of isolate VA1 under aerobic culture conditions, but was not essential for growth. These microorganisms, including isolate VA1, were able to grow with vigorous shaking in atmospheric air. It can be speculated that thiosulfate functions as a reducer for reactive oxygen species such as hydrogen peroxide.

Description of Pyrobaculum calidifontis sp. nov.

Pyrobaculum calidifontis (ca.li.di.fon'tis. L. adj. calidus hot; L. masc. n. fons spring, fountain; M.L. masc. n. calidifontis hot spring).

Rod-shaped cells are usually 1.5 to $10 \mu \mathrm{m}$ long and 0.5 to $1.0 \mu \mathrm{m}$ wide. Motile. Only heterotrophic growth has been observed. Grows on $0.1 \%$ yeast extract, tryptone, nutrient broth, peptone, or Casamino acids. Highest growth rates were observed with $1.0 \%$ tryptone with $0.1 \%$ yeast extract. Facultatively aerobic. Oxygen (aerobic) and nitrate (anaerobic) serve as electron acceptors. Elemental sulfur inhibits aerobic cell growth. Thiosulfate enhances aerobic cell growth, but is not essential. Aerobic growth occurs between 75 and $100{ }^{\circ} \mathrm{C}$ (optimum, 90 to $95^{\circ} \mathrm{C}$ ), at $\mathrm{pH} 5.5$ to 8.0 (optimum, $\mathrm{pH} 7.0$ ), at 0 to $0.8 \% \mathrm{NaCl}$ (optimum, $0 \%$ ). The $\mathrm{G}+\mathrm{C}$ content of genomic DNA is about $51 \mathrm{~mol} \%$. The $16 \mathrm{~S}$ rRNA sequence displays 97.9\% similarity to Pyrobaculum oguniense, $97.7 \%$ to $P$. aerophilum, $97.6 \%$ to $P$. arsenaticum, $97.5 \%$ to $P$. islandicum and 96.4\% to Thermoproteus tenax. Type strain: Pyrobaculum calidifontis VA1, JCM 11548, Wako, Japan (isolated from Calamba, Laguna, the Philippines).

Table 1. DNA-DNA hybridization between Pyrobaculum calidifontis strain VA1, other species of the genus Pyrobaculum, and Thermoproteus tenax.

\begin{tabular}{lllllll}
\hline Source of microplate-bound DNA & \multicolumn{6}{l}{ \% Homology with sources of photobiotin-labeled DNA } \\
\cline { 2 - 7 } & Strain VA1 & P. aerophilum & P. oguniense & P. islandicum & P. organotrophum & T. tenax \\
\hline P. calidifontis strain VA1 & 100 & 18 & 6 & 0 & 2 & 0 \\
P. oguniense & 11 & 55 & 100 & 2 & 9 & 0 \\
\hline
\end{tabular}




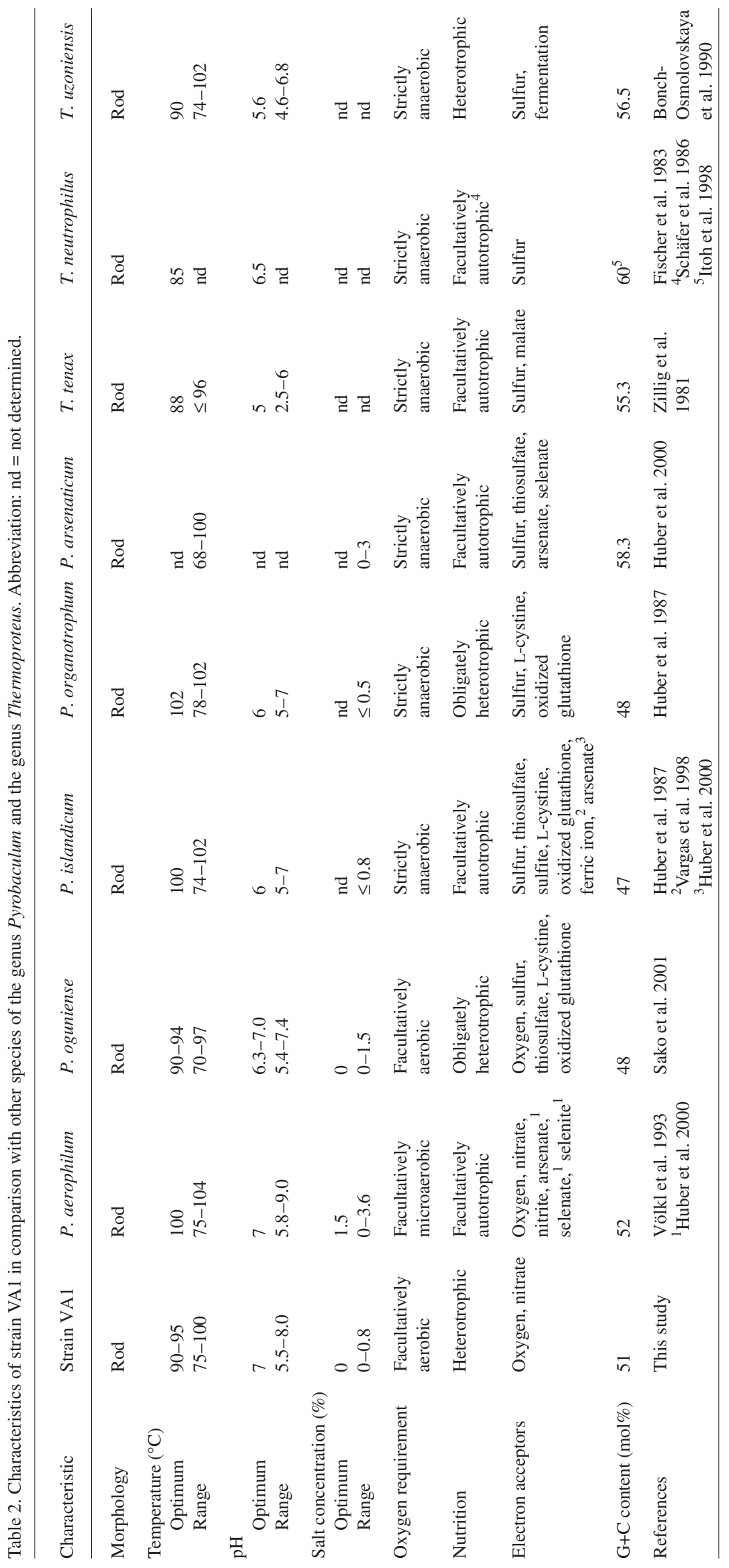




\section{References}

Adams, M.W.W. and R.M. Kelly. 1998. Finding and using hyperthermophilic enzymes. Trends Biotechnol. 16:329-332.

Amend, J.P. and E.L. Shock. 2001. Energetics of overall metabolic reactions of thermophilic and hyperthermophilic Archaea and Bacteria. FEMS Microbiol. Rev. 25:175-243.

Balch, W.E., G.E. Fox, L.J. Magrum, C.R. Woese and R.S. Wolfe. 1979. Methanogens: reevaluation of a unique biological group. Microbiol. Rev. 43:260-296.

Blöchl, E., R. Rachel, S. Burggraf, D. Hafenbradl, H.W. Jannasch and K.O. Stetter. 1997. Pyrolobus fumarii, gen. and sp. nov., represents a novel group of archaea, extending the upper temperature limit for life to $113{ }^{\circ} \mathrm{C}$. Extremophiles 1:14-21.

Bonch-Osmolovskaya, E.A., M.L. Miroshnichenko, N.A. Kostrikina, N.A. Chernych and G.A. Zavarzin. 1990. Thermoproteus uzoniensis sp. nov., a new extremely thermophilic archaebacterium from Kamchatka continental hot springs. Arch. Microbiol. 154: $556-559$.

Brock, T.D., K.M. Brock, R.T. Belly and R.L. Weiss. 1972. Sulfolobus: a new genus of sulfur-oxidizing bacteria living at low $\mathrm{pH}$ and high temperature. Arch. Mikrobiol. 84:54-68.

Castresana, J. and D. Moreira. 1999. Respiratory chains in the last common ancestor of living organisms. J. Mol. Evol. 49:453-460.

Ezaki, T., Y. Hashimoto and E. Yabuuchi. 1989. Fluorometric deoxyribonucleic acid-deoxyribonucleic acid hybridization in microdilution wells as an alternative to membrane filter hybridization in which radioisotopes are used to determine genetic relatedness among bacterial strains. Int. J. Syst. Bacteriol. 39:224-229.

Felsenstein, J. 1981. Evolutionary trees from DNA sequences: a maximum likelihood approach. J. Mol. Evol. 17:368-376.

Fischer, F., W. Zillig, K.O. Stetter and G. Schreiber. 1983. Chemolithoautotrophic metabolism of anaerobic extremely thermophilic archaebacteria. Nature 301:511-513.

Grogan, D.W. 1989. Phenotypic characterization of the archaebacterial genus Sulfolobus: comparison of five wild-type strains. J. Bacteriol. 171:6710-6719.

Hara, T., T. Shimoda, K. Nonaka and S. Ogata. 1991. Colorimetric detection of DNA-DNA hybridization microdilution wells for taxonomic application on bacterial strains. J. Ferment. Bioeng. 72: $122-124$.

Huber, H. and K.O. Stetter. 1998. Hyperthermophiles and their possible potential in biotechnology. J. Biotechnol. 64:39-52.

Huber, R., J.K. Kristjansson and K.O. Stetter. 1987. Pyrobaculum gen. nov., a new genus of neutrophilic, rod-shaped archaebacteria from continental solfataras growing optimally at $100{ }^{\circ} \mathrm{C}$. Arch. Microbiol. 149:95-101.

Huber, R., T. Wilharm, D. Huber, A. Trincone, S. Burggraf, H. König, R. Rachel, I. Rockinger, H. Fricke and K.O. Stetter. 1992. Aquifex pyrophilus gen. nov. sp. nov., represents a novel group of marine hyperthermophilic hydrogen-oxidizing bacteria. Syst. Appl. Microbiol. 15:340-351.

Huber, R., M. Sacher, A. Vollmann, H. Huber and D. Rose. 2000. Respiration of arsenate and selenate by hyperthermophilic archaea. Syst. Appl. Microbiol. 23:305-314.

Itoh, T., K. Suzuki and T. Nakase. 1998. Occurrence of introns in the 16S rRNA genes of members of the genus Thermoproteus. Arch. Microbiol. 170:155-161.
Itoh, T., K. Suzuki, P.C. Sanchez and T. Nakase. 1999. Caldivirga maquilingensis gen. nov., sp. nov., a new genus of rod-shaped crenarchaeote isolated from a hot spring in the Philippines. Int. J. Syst. Bacteriol. 49:1157-1163.

Kurosawa, N., Y.H. Itoh, T. Iwai, A. Sugai, I. Uda, N. Kimura, T. Horiuchi and T. Itoh. 1998. Sulfurisphaera ohwakuensis gen. nov., sp. nov., a novel extremely thermophilic acidophile of the order Sulfolobales. Int. J. Syst. Bacteriol. 48:451-456.

Olsen, G.J., H. Matsuda, R. Hagstrom and R. Overbeek. 1994. fastDNAmL: a tool for construction of phylogenetic trees of DNA sequences using maximum likelihood. Comput. Appl. Biosci. 10: 41-48.

Saitou, N. and M. Nei. 1987. The neighbor-joining method: a new method for reconstructing phylogenetic trees. Mol. Biol. Evol. $4: 406-425$.

Sako, Y., N. Nomura, A. Uchida, Y. Ishida, H. Morii, Y. Koga, T. Hoaki and T. Maruyama. 1996. Aeropyrum pernix gen. nov., sp. nov., a novel aerobic hyperthermophilic archaeon growing at temperatures up to $100^{\circ} \mathrm{C}$. Int. J. Syst. Bacteriol. 46:1070-1077.

Sako, Y., T. Nunoura and A. Uchida. 2001. Pyrobaculum oguniense sp. nov., a novel facultatively aerobic and hyperthermophilic archaeon growing at up to $97{ }^{\circ} \mathrm{C}$. Int. J. Syst. Evol. Microbiol. 51:303-309.

Sambrook, J. and D.W. Russell. 2001. Molecular cloning: A laboratory manual. 3rd Edn. Cold Spring Harbor Laboratory Press, Cold Spring Harbor, New York.

Schäfer, S., C. Barkowski and G. Fuchs. 1986. Carbon assimilation by the autotrophic thermophilic archaebacterium Thermoproteus neutrophilus. Arch. Microbiol. 146:301-308.

Segerer, A., A. Neuner, J.K. Kristjansson and K.O. Stetter. 1986. Acidianus infernus gen. nov., sp. nov., and Acidianus brierleyi comb. nov.: facultatively aerobic, extremely acidophilic thermophilic sulfur-metabolizing archaebacteria. Int. J. Syst. Bacteriol. 36:559-564.

Stetter, K.O. 1999. Extremophiles and their adaptation to hot environments. FEBS Lett. 452:22-25.

Takagi, H., O. Shida, K. Kadowaki, K. Komagata and S. Udaka. 1993. Characterization of Bacillus brevis with descriptions of Bacillus migulanus sp. nov., Bacillus choshinensis sp. nov., Bacillus parabrevis sp. nov., and Bacillus galactophilus sp. nov. Int. J. Syst. Bacteriol. 43:221-231.

Tamaoka, J. and K. Komagata. 1984. Determination of DNA-base composition by reversed-phase high-performance liquid chromatography. FEMS Mcrobiol. Lett. 25:125-128.

Thompson, J.D., D.G. Higgins and T.J. Gibson. 1994. CLUSTAL W: improving the sensitivity of progressive multiple sequence alignment through sequence weighting, position-specific gap penalties and weight matrix choice. Nucleic Acids Res. 22:4673-4680.

Vargas, M., K. Kashefi, E.L. Blunt-Harris and D.R. Lovley. 1998. Microbiological evidence for Fe(III) reduction on early Earth. Nature 395:65-67.

Völkl, P., R. Huber, E. Drobner, R. Rachel, S. Burggraf, A. Trincone and K.O. Stetter. 1993. Pyrobaculum aerophilum sp. nov., a novel nitrate-reducing hyperthermophilic archaeum. Appl. Environ. Microbiol. 59:2918-2926.

Zillig, W., K.O. Stetter, W. Schäfer, D. Janekovic, S. Wunderl, I. Holz and P. Palm. 1981. Thermoproteales: a novel type of extremely thermoacidophilic anaerobic archaebacteria isolated from Icelandic solfataras. Zentbl. Bakteriol. Mikrobiol. Hyg. 1 Abt. Orig. C 2: 205-227. 

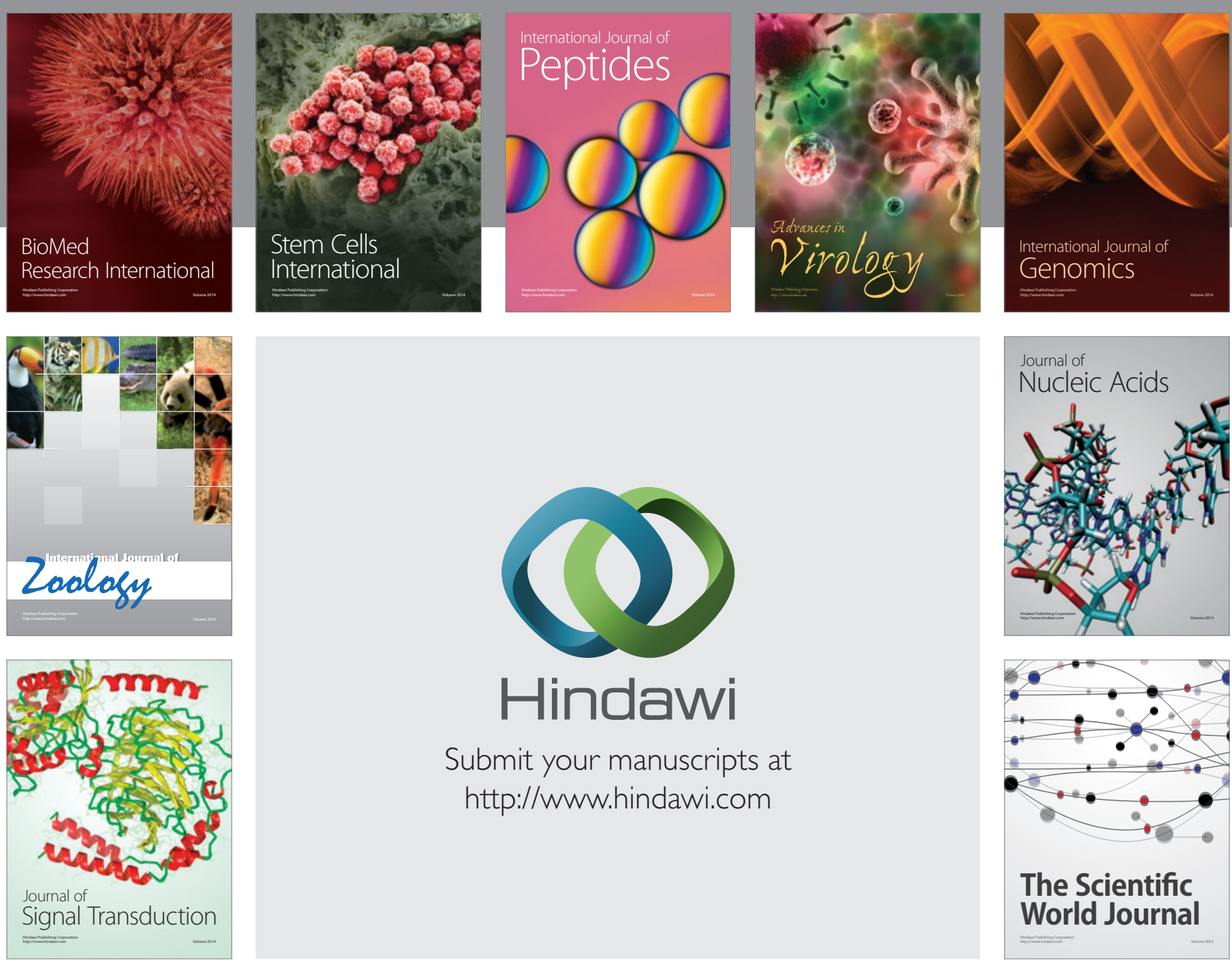

Submit your manuscripts at

http://www.hindawi.com
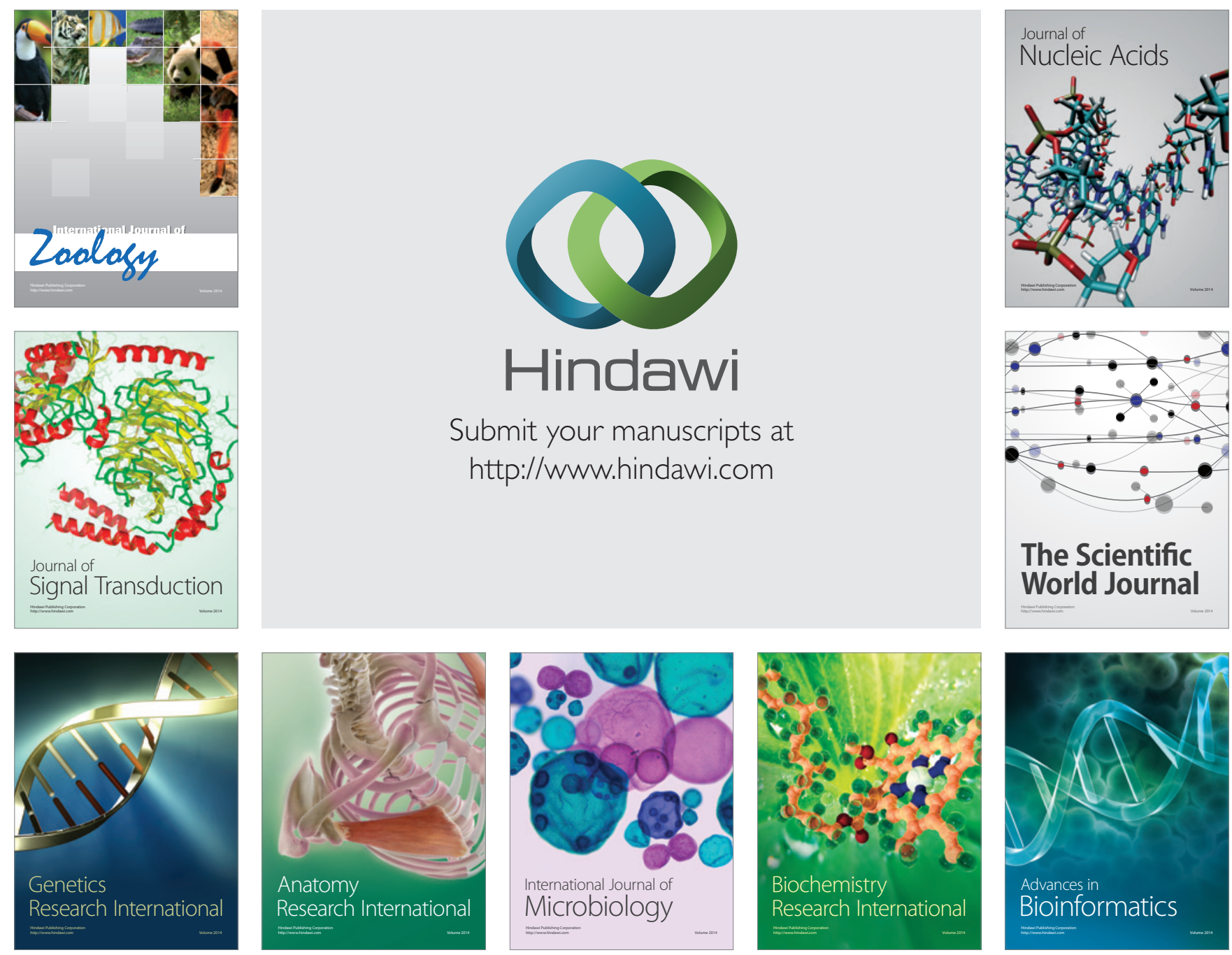

The Scientific World Journal
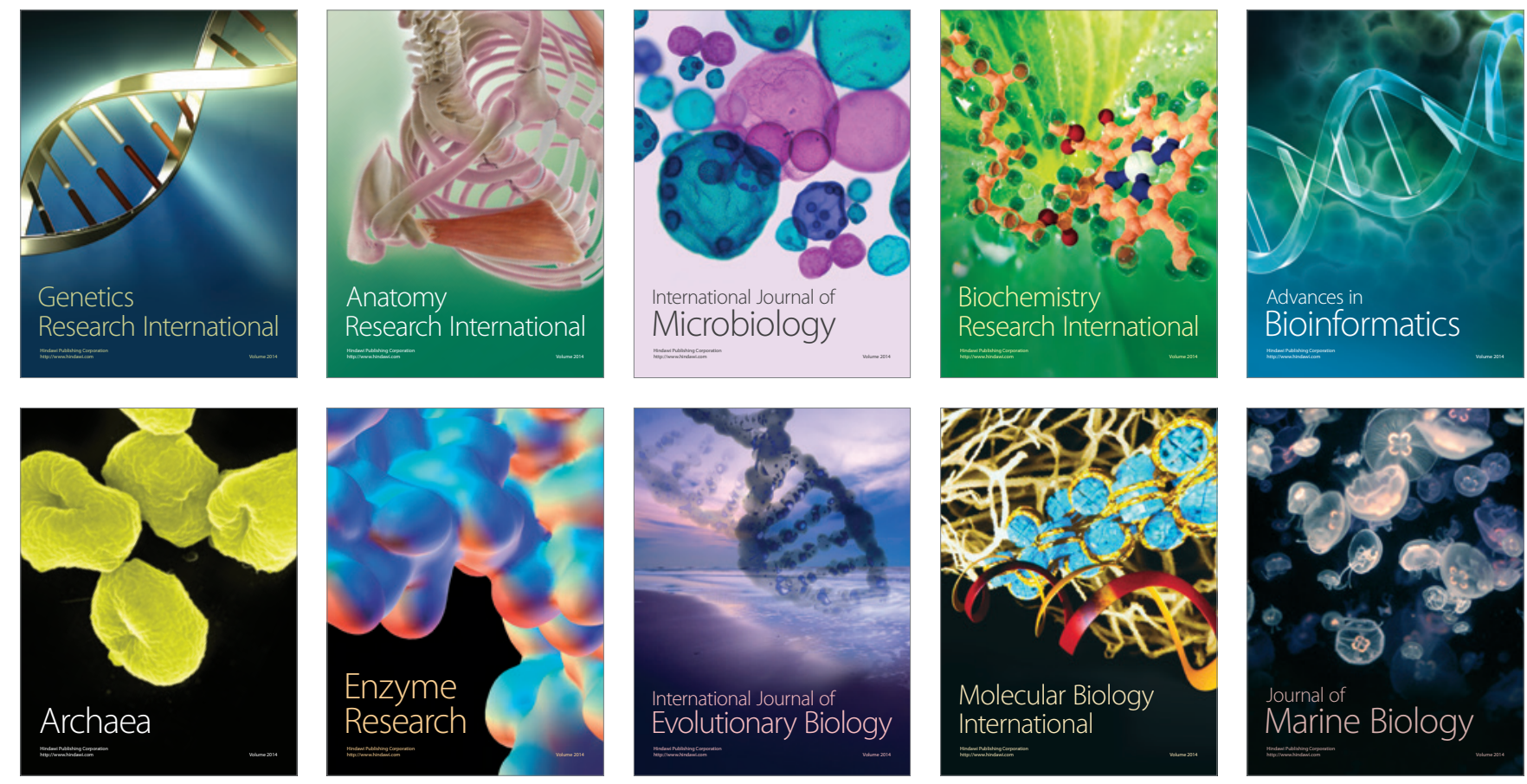